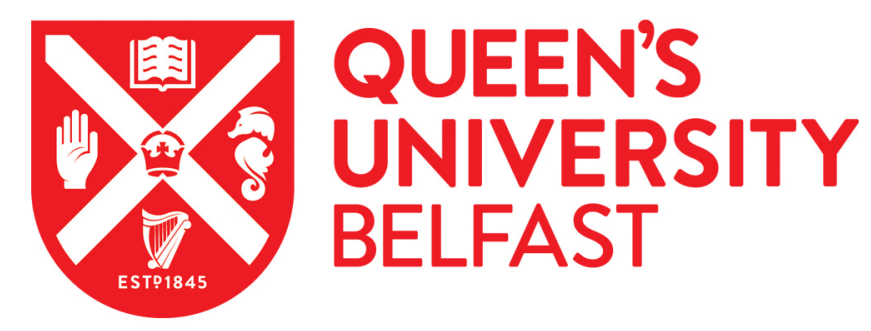

\title{
Experimental Electronic Sound as Playful Articulation of a Compromised Sociality in Iran
}

Bastani, H. (2019). Experimental Electronic Sound as Playful Articulation of a Compromised Sociality in Iran. Paper presented at BFE/SFE joint autumn conference, London, Nov. 2019, London, United Kingdom. https://static1.squarespace.com/static/5c98b4fe4d546e5350d29694/t/5db41ef02ca7a63a6d3f3250/1572085489 316/BFE_SFE_HB_Nov2019_WebSite.pdf

Queen's University Belfast - Research Portal:

Link to publication record in Queen's University Belfast Research Portal

Publisher rights

Copyright 2019 The Author.

\section{General rights}

Copyright for the publications made accessible via the Queen's University Belfast Research Portal is retained by the author(s) and / or other copyright owners and it is a condition of accessing these publications that users recognise and abide by the legal requirements associated with these rights.

Take down policy

The Research Portal is Queen's institutional repository that provides access to Queen's research output. Every effort has been made to ensure that content in the Research Portal does not infringe any person's rights, or applicable UK laws. If you discover content in the Research Portal that you believe breaches copyright or violates any law, please contact openaccess@qub.ac.uk. 


\section{Experimental Electronic Sound as Playful Articulation of a Compromised Sociality in Iran \\ Paper presented at BFE/SFE joint autumn conference, City University London, Nov. 2019 \\ Hadi Bastani | hadibastani.com | hbastani01@qub.ac.uk}

The Experimental Electronic Music Scene in Iran, which I will refer to from now on using its initials EEMSI, can be described in terms of its aesthetics as well as the relations it has established as a trans-local phenomenon emerged in contact with digital technologies and the internet—relations that are embedded, while help perpetuating, certain networks of cosmopolitan musical affinity. The function of such networks is of course broader than that of providing space for conversation, sharing, learning and collaboration. These networks equip the participants, in varying degrees, with a sense of belonging to something bigger than what happens in the town. In our case, these involve forms of aesthetic exploration that afford new formations of identity as well as new imaginaries regarding alternative modes of sociality that are performed outside the reach and control of 'traditional' authorities, like the central government or nuclear family. In the particular case of Iran, due to the state's rather obsessive tendency to monitor and regulate the social while not tolerating serious critique, such a possibility is of remarkable significance. Precisely then, because of its tangled relationship and constant exchange with the ideological-political, also with the social and ecological in Iran, and their performed, individualised embodiments, EEMSI can be simultaneously viewed as a localised occurrence. It is, therefore, important to note that the scene's musico(logics) and identities are not created merely in response to the local or global 'flows', and note that these are performatively taken shape across a range of fundamentally composite discourses and practices.

In the practical material sense, EEMSI's emergence can be understood in relation to what Georgina Born (2005) has termed 'relayed creativity'. Emphasising 
the use of digital media in surpassing the capacity of material artefacts to stop the flow of re-creation, Born notes: (ibid, 26)

Digitized music $[\ldots]$ is continually, immanently open to re-creation. Distributed across space, time and persons, music can become an object of recurrent decomposition, composition and re-composition by a series of creative agents. We need a new term for this capacity: I suggest relayed creativity.

EEMSI is generally an urban middle-class phenomenon, characterised by activities of educated and secularist computer musicians, digital artists, media producers, and creative coders. It is mostly concentrated in the capital Tehran and is largely represented, 'on the stage', by male producers of 25 to 35 years old, although the gender balance has been shifting in favour of more female participation.

In the cyberspace, the first indications of an electronic music practice in Iran emerged on Facebook and Soundcloud around 2010, one year into President Ahmadinejad's second term in office. Inside the country, the first public appearances took place in galleries across the capital in the same year. The initial activities involved workshops, presentations, talks, and later performances and installations. The public face of this scene consists of two internationally-known festivals namely Tehran Annual Digital Arts Exhibition aka TADAEX and SET Experimental Arts Events aka SET Festival.

Galleries like Tarrāhān-e Āzād, Mohsen, and Aun were the first public hosts of experimental electronic sound in Iran. In the private domain, for instance in gatherings and parties, however, these new forms were already known to a limited number of friendship circles, from around 2008. The fact that such activities found a way to the public domain rather quickly and without causing any serious resistance from the state is crucial, because a large range of musical endeavours still cannot be represented in such a way, hence inevitably remaining as a private interest or an 'underground' adventure. This is due to the state's ideologically-rooted political scepticism towards musicking Iranians, which can be currently discerned in its hostility towards certain genres of popular music such as rap, hip-hop, and house. 
When the early signs of an emergent experimental electronic music practice in Iran surfaced, I was based in Paris as a music tech student. One night I saw a post from a friend on Facebook that was linked to a piece of music on Soundcloud. The music was Street 1 by Umchunga. It was labelled with the hashtag 'Idm'. In the matter of few months many more similar cases appeared on the internet. The sonic palette from which the 'new music' coming from Iran drew did not belong to the practice of the composers and producers I had known. When I left the country, in 2009, rock, blues, country, and jazz influences were still surfacing in demos and occasional (mostly private) gigs. Certain folk music elements from the Jewish heritage and the Balkan area, the kinds one would for instance hear in the work of Goran Bergović had also found a way to the work made by a few acts. Some rather conventional electronic pieces-a few inspired by the use of software such as Fruity Loops and $\underline{\text { Reason, }}$ others influenced by synth pop and industrial rock aesthetics; the likes of Depeche Mode's and Nine Inch Nails'-could also be heard here and there. Incorporation of elements borrowed from Iranian classical and folk music within the above-mentioned forms by a few rock, funk, and 'fusion' jazz bands, was another trend of the time. But, I had never previously heard of an electronic music from Iran inspired by ambient, glitch, idm, and noise aesthetics.

The practices I am concerned with here, typically do not offer any explicit features that may be experienced as stereotypically Iranian, with only a very few exceptions. Here lies a particularity of this scene that I would like to discuss here; its performative and discursive resistance towards almost anything 'mainstream'; be it music, politics, celebrity culture, pop culture in general, western understanding of Iranian culture/arts and music, Iranian ideals of Persianism or Islamism, exaggerations on the Western Media about total lack of freedom in Iran, omnipresent conflicts, and oppression, and the Iranian positivistic Reformist narrative of an absolutely progressive society, steadily pacing towards secular democracy. Although, or perhaps because EEMSI is highly politically-conscious, it distances itself from such narratives. 
Within the genric lexicon, EEMSI sounds can be categorised under terms such as ambient, drone, experimental, idm, noise, and glitch, as mentioned earlier. Generally speaking, we are in the realm of electronic and computer music, performed mainly with laptops, often with visual accompaniment, although all with an experimental touch! This experimentalism and lack of stereotypical references to Iranian culture, society, and politics are key characteristics of EEMSI. At the first glance this absence of stereotypical specificity, by which I am referring to the discourse and practice that typically labels and defines, for Iranian and non-Iranian audiences, what constitutes Iranian music or art, is paramount.

This absence, is in fact an escape, from this very cycle that defines, and in so doing limits arts and music in Iran. As such, it is an exit, towards a new musical future: a 'future' that becomes, as Roland Barthes would say, 'the essential destruction of the past.' (Barthes 1976,178) And, this 'past' would be one in which Iranian culture seems to have been stuck, increasingly so due to the dogmatic and often revivalist performance of the Islamic Republic. This is also a past invented around the name Iran in the West since many decades ago; one which involves images and description that portray Iran simultaneously as an exotic destination with a rich ancient culture, welcoming and kind people, and a terrorist state or nation, that's waging war all over the world. These are highly stereotypical, unnuanced, easy to grasp and, therefore, powerful, vortex-like descriptions that swallow almost anything that comes out of Iran — be it politics, science, or arts and music — spitting them out from the other side under a certain number of ready-made, solidified categories.

The absence or escape that I identified as a key feature of EEMSI, is also the result of a pragmatic approach to making music in an environment, in which music, sound, and voice are heavily politicised and moralised. The coded language of abstract sounds and images common to EEMSI products has, in fact, deep roots and precedence in Iranian culture; these are recurrent patterns that yet again have found specific social functions, this time in the form of experimental electronic sound. 
The experimentalism that I refer to here is neither intended as a sort of aesthetic judgment in relation to the 'finished' work and/or of the artistic process 'behind' it, nor as a direct pointer for American experimentalism of the 1950s and its later offshoots, although EEMSI would not be totally unrelated to that movement either. My use of the term, however, does draw from Benjamin Piekut's holistic view over American Experimentalism (2011). Through a wide lens as such—that is capable of accommodating my interlocutors' descriptions-experimentalism consists of a mode of negotiation in an environment with no significant 'tradition' in electronic music; an environment that's not particularly well-structured for the requirements of an amateur or professional in music or sound either. The kind of experimentalism I'm concerned with here, therefore, involves strategies of navigating not only the sonic and the technological but also the social, ethical, legal, ideological-political, and the economic. It takes place through a mediation between the 'emergent' and the more established networks of creative practice in Iran, and beyond. It manifests in trials and errors, successes and failures. It engages with the practicalities and contingencies of presenting a new musical form and rendering it intelligible for others through different processes of 'translation'-i.e. through performances, talks, interviews, reviews, discussions, and articles, also through encounters with other artists, producers, audiences, government officials, curators, and publishers, as well as with festivals, residencies, academies, galleries and venues, materials, technologies, concepts, and imaginaries.

Professionals and amateurs in music and sound in Iran were broadly introduced to music production and sound synthesis software according to the following three generic patterns: First, accidental encounter. During Mahmoud Ahmadinejad's presidency (2005-2013), due to increasingly intensified sanctions put in place by the US and the UN security council on Iran's economy, no financial transaction to or from Iranian banks for ordinary citizens was possible. Nobody could purchase anything via the Internet. The situation still remains more or less the same, the only difference now is that there is an internally functional network, which people can 
use to buy stuff online using Iranian bank accounts from inside the country. But during the politically and economically turbulent years of Ahmadinejad's presidency, in response to the circumstances created by the sanctions as well as by the state's economic and political mismanagement, and in tune with the lack of proper copy right laws in Iran, a hack software market grew. Shopping malls and tech stores like Pāyétakht and Bazar Rezā in Tehran were flooded with CD and DVD bundles, that offered a large variety of copied and hacked software. Among the very many programmes on a DVD, one could accidentally stumble upon a music production software, and many people did: for instance the famous hip-hop and electronic producer in Iran Alireza Poursohoolat aka Mezrab, with whom I interviewed on 23 December 2018. Second form of encounter took place in music studios. As a result of the Reformist government's significantly more open policies with regards to cultural production (1997-2005), two parallel pop music movements emerged: a mainstream scene that was supported by the state and was represented in famous venues and music stores, also through the National TV and Radio, and a grassroots alternative pop scene that was mainly represented by the activities of rock, jazz, and hip-hop acts. Although rap and hip-hop gigs were never granted the state-required permission, a few rock and jazz bands found opportunities to publicly and legally present their material in smaller venues and in rarer occasions sell their records in music stores. As a result and in response to such changes in the music scene, production studios mushroomed. These provided a space for musicians and producers to get exposed to software and hardware affordances. The third form of introduction took place within Film, TV, Radio, and advertisement industry, mainly for the purposes of putting sound on or designing sound for videos. Experimenting with digital interfaces, brought about new ways of doing and thinking sound as well as new forms of and reasons for connectivity with peers, practices, and materials in other parts of the world. In contact with the proliferation of more affordable and efficient internet connections, these circumstances fundamentally changed for many, like myself, the way they approached music or sound. EEMSI is the offspring of this change. 
To locate EEMSI properly, however, one cannot escape discussing the state's heavy control over cultural production in general and the domain of pop culture in particular. EEMSI's aesthetics is a locus for the crystallisation of a concurrent resistance against, and embodiment of, an aggressively enforced, 'ambiguous' or confused, and confusing, control. Through this lens, the scene's aesthetics is shaped as a result of a play between the emergent, digitally-enabled modes of creative practice and forms of sociality, rooted in a cosmopolitan ethos shared among producers, who operate as active nodes within sufficiently decentralised, transnational affinity networks based in the cyberspace, and the internalised, individualised, embodied effects of ideological-political and moral control in Iran.

To understand EEMSI is partly to understand this control. There is something unique about the form, reach, and texture of control and socio-cultural processes in Iran. It is exhausting to be forced to operate within a perpetual state of 'inbetween-ness' and insecurity. The existence of such a state relates to the conditions of political and economic uncertainty but also to deep-rooted mechanisms of dogmatic ethical-moral judgement. Internalised to an extent within the society, such mechanisms manifest even in the most insignificant situations in daily lives of people in Iran. They constantly have to process in various situations what is (not) permitted; what can(not) be expressed; what is the hidden meaning of everything said or done; what is essentially morally right and what is wrong.

One may say that it is not so different in many other societies. That may be generally true, but the devil is in the detail here. What I'm trying to convey is not so much about control per se than it is about its invasive and heavily moralised boundaries and its chilling, risk-laden, fuzziness. It is about pervasive but hardly detectable mechanisms that render a large category of practices, behaviours, interests, successes, failures, orientations, decisions, and even thoughts in Iran almost (im)permissible and potentially dangerous. I have termed this machinic assemblage that filters and regulates the social in such a unique way in Iran the amorphous regulatorium and its output the almost-(im)permissibles. 
This amorphous and semi-autonomous machine is an agentive force that currently operates at the conjunction of radically different worlds of cyber-powered imaginaries and social 'realities'-although the two are increasingly intertwinedthe converging worlds of mad technological acceleration and neoliberal capitalism, and the isolated worlds of ideological-political resistance against the latter's transformative cultural force. The amorphous regulatorium works towards creating a context for a legitimate and justified resistance against neoliberal capitalism's uncompromising force and, as such, guarantees the sustenance of ideological-political power in Iran through continuously renewed processes of ethical-moral-legal judgement. To clarify, I am not advocating any form of conspiracy theory here. I do not mean that such an elaborate system, or machine, is designed and implemented by the 'regime'. Rather, I have argued that this machinic operation has emerged as a result of the establishment's performance.

As a new phenomenon within the art/music scene in Iran, EEMSI's emergence in the public domain around 2009 can be understood in relation to 'Jacques Attali's (1985) formulation of a final utopian "political economy" of music- "composition"-by which the latter means each individuals capacity to construct the soundscape to and of her own life.' (Waters 2015, 25 - emphasis mine). In a society in which the social is seriously compromised by a politics based on dogmatic and vague ideologies that feed from revivalist interpretations of a revolution that took place 40 years ago, and an ideal Islamic society that presumably was established around 14 centuries ago, this focus on the individual is of crucial significance.

Due to the contraction of political air in two stages in Iran-firstly as a result of the hard liners' endeavours to reverse the Reformist government's cultural and political achievements, particularly from around 1999 or 2000 to 2005, and the Reformists' complacent conformism — a process that has continued to this date-and later following a series of widespread protests, known as the Iranian Green Movement, against the results of the 2009 presidential elections that met with the system's 
iron hand — the society was only prepared for minor changes in around 2009. Having emerged in such a time and place, EEMSI delivered exactly that: a minor, but significant, change.

Borrowing from Pedro Rebelo's The Local and the Distributed in Sonic Arts (2014), I would close by noting that in the very act of avoiding explicit social references, the 'sound' of experimental electronic music in Iran 'at its most evocative, becomes the trigger for [playfully] articulating lived experience of place and a reality of listening [that producers and audiences] share [as] [t] he everyday acts as a vehicle for expressing the personal, the societal and the political, which one hears, and others do too...' (696)

The emergent, digitally-enabled modalities of practice and sociality within Iranian art/music scene articulate sameness and difference in diverse and complex ways. These are formed in negotiation with and in response to the broader materialsocial-economic-political-technological-ecological-biological forces, but also generate new relations, aesthetics, and agencies that distort, reconfigure, and transform those in different ways within a feedback system. Arguing against some commentators, who have labelled the scene, because of its unique aesthetics, as 'conformist', 'passive', and therefore 'politically unjustified', I would note that in playfully aestheticizing and publicising lived experience of the place in new ways, the reconfiguring(s) described earlier, however niche and marginal, are, as such, inevitably political, and in their radical novelty actively disruptive. As Jacques Rancière has argued (2013, xiii):

The essence of politics consists in interrupting the distribution of the sensible by supplementing it with those who have no part in the perceptual coordinates of the community, thereby, modifying the very aesthetic-political field of possibility.

Although in its earliest ambient/shoegaze/downtempo form, EEMSI started by articulating the 'background'-bedrooms, basements, late night web surfing, online chats, precious music discoveries, listening, and dreaming-by that very act of making the 'background', the margins, the playful, and the 'repressed', audible, it 
unlocked new avenues for channelling creative energy within the music scene in Iran. The early manifestations of EEMSI were, nevertheless, hopeful of a musical future in which experimental electronic music might appear in the 'foreground' of social conduct, and be confidently and proudly shared. Rather surprisingly, this happened, and as it did, the scene rapidly grew. The establishment did not take serious issues with it. Although radically new, the initially gentle sound and 'image' of the 'repressed' did not bother the 'oppressor'. In a country in which many forms of music still cannot be represented; where hardly anything gets professionally done due to political-economic uncertainties - as agents of perpetual ethical contingency-and their embodied artefacts across the social-material field of possibility, there is a thriving experimental electronic music scene, ironically but pragmatically, being shaped. And it is no longer gentle. It is confident and growling, morphing into new forms as younger producers bring in their influences, older ones become more experienced, and social-material-technological landscape shifts. The experimental electronic music scene, as such, may soon not be so experimental in the ways described in this text anymore, as, in the politically-forced absence of many other forms, increasingly constitutes an electronic music mainstream, audible on the surface of the society. There are, however, new forms still waiting to become; to find a way out from the quiet darkness of bedrooms and basements to the loud darkness of black box venues. Thriving in the dark, EEMSI is becoming the loudest voice of 'Iranian' music, representing (in every sense) a new musical and sonic possibility. 